\title{
Hotelling's location model with negative network externalities
}

Citation for published version (APA):

Peters, H., Schröder, M., \& Vermeulen, D. (2018). Hotelling's location model with negative network externalities. International Journal of Game Theory, 47(3), 811-837. https://doi.org/10.1007/s00182-0180615-0

Document status and date:

Published: 01/09/2018

DOI:

10.1007/s00182-018-0615-0

Document Version:

Publisher's PDF, also known as Version of record

Document license:

Taverne

Please check the document version of this publication:

- A submitted manuscript is the version of the article upon submission and before peer-review. There can be important differences between the submitted version and the official published version of record.

People interested in the research are advised to contact the author for the final version of the publication, or visit the DOI to the publisher's website.

- The final author version and the galley proof are versions of the publication after peer review.

- The final published version features the final layout of the paper including the volume, issue and page numbers.

Link to publication

\footnotetext{
General rights rights.

- You may freely distribute the URL identifying the publication in the public portal. please follow below link for the End User Agreement:

www.umlib.nl/taverne-license

Take down policy

If you believe that this document breaches copyright please contact us at:

repository@maastrichtuniversity.nl

providing details and we will investigate your claim.
}

Copyright and moral rights for the publications made accessible in the public portal are retained by the authors and/or other copyright owners and it is a condition of accessing publications that users recognise and abide by the legal requirements associated with these

- Users may download and print one copy of any publication from the public portal for the purpose of private study or research.

- You may not further distribute the material or use it for any profit-making activity or commercial gain

If the publication is distributed under the terms of Article $25 \mathrm{fa}$ of the Dutch Copyright Act, indicated by the "Taverne" license above, 


\title{
Hotelling's location model with negative network externalities
}

\author{
Hans Peters ${ }^{1} \cdot$ Marc Schröder $^{2}$ - Dries Vermeulen ${ }^{1}$
}

\begin{abstract}
We study a variation of Hotelling's location model in which consumers choose between firms based on travel distances as well as the number of consumers visiting each firm. The model in which the network externality is the same for all firms was proposed by Kohlberg (Econ Lett 11:211-216, 1983), who claims that no equilibrium exists for more than two firms. We assume the network effects to be linear and, in contrast to the claim in Kohlberg (Econ Lett 11:211-216, 1983), derive a condition under which a subgame perfect Nash equilibrium exists for four and six firms. Moreover, we show that for more than two firms the equilibrium locations of the firms are different from the equilibrium locations in Hotelling's location model. Our results suggest that a subgame perfect Nash equilibrium exists if and only if the number of firms is even. We also provide examples of subgame perfect equilibria in which the network externality is different for some of the firms.
\end{abstract}

Keywords Hotelling's location model · Network externalities · Subgame perfect Nash equilibrium

$\bowtie \quad$ Marc Schröder

marc.schroeder@oms.rwth-aachen.de

Hans Peters

h.peters@maastrichtuniversity.nl

Dries Vermeulen

d.vermeulen@maastrichtuniversity.nl

1 Department of Quantitative Economics, Maastricht University, Maastricht, The Netherlands

2 School of Business and Economics, RWTH Aachen University, Aachen, Germany 


\section{Introduction}

The seminal paper of Hotelling (1929) describes a simple model of spatial competition in which two firms compete for consumers. There are many generalizations of the model that focus on different aspects of the problem, like the number of competitors, the pricing behavior of the firms, and/or the market structure. We consider a version in which firms want to maximize their market share by means of their location in the presence of negative network externalities. The externality can be interpreted as for example congestion: the larger the market share of a firm, the higher its expected waiting time, or as snobbery: the smaller the market share of a firm, the higher its prestige. This model applies particularly to products of which the price is fixed, such as newspapers or brand products, and to political competition as introduced by Downs (1957).

Hotelling's location model considers a game between $n$ firms on the unit interval. Consumers are assumed to be evenly distributed along the interval and want to visit exactly one firm. The play of the game is as follows. First, each firm simultaneously chooses a location, and second, each consumer visits the closest firm. Despite the simple structure of the game, the payoff function of a firm is often discontinuous. In order to circumvent this problem, Kohlberg (1983) proposed a modification in which consumers care about the travel time as well as the expected waiting time for service. The inclusion of these network effects into the model guarantees that the payoff function of each firm is continuous. Despite this desired feature, Kohlberg (1983) states that for $n=3$ it is easy to verify that there is no equilibrium in which two firms locate in the same place, and proves that there is no equilibrium if the three firms locate at a different location. Then he concludes that the game has no equilibrium for more than two firms and refers to Kohlberg (1982) for a proof for an arbitrary number of firms. Kohlberg (1982) proves that for $n>3$ no equilibrium exists if the locations of the firms are different. He then claims that it is easy to verify that in equilibrium all the firm locations must be different and concludes that the game has no equilibrium for more than two firms. The claim that in equilibrium no two firms locate in the same place is based on the result for $n=3$. However, he does not provide any intuition why the claim should be correct for arbitrary $n$, especially because the unique equilibrium for two firms is such that both firms locate at the center of the market.

We assume that the network externality is linear in the number of consumers visiting a firm and show that the claim that all the firm locations must be different is incorrect for $n \in\{4,6\}$. Our main results are as follows.

Results First, we assume that the network externality is the same for all firms. Since the game played between firms and consumers involves an element of timing, we focus on subgame perfect Nash equilibria. We derive a necessary and sufficient condition under which a subgame perfect equilibrium exists for two, four and six firms. For four and six firms, we find that the network effect should be sufficiently large for a subgame perfect equilibrium to exist. We also show that the game has no subgame perfect equilibrium for three and five firms. Based on these results, we conjecture that the game has a subgame perfect equilibrium if and only if the number of firms is even and the network effects are sufficiently large.

Second, we characterize the locations of the firms in a subgame perfect Nash equilibrium. For four and six firms, we show that there are two firms that locate at the center 
of the market, which is in contrast to the claim of Kohlberg that no two firms locate in the same location. The equilibrium locations for four and six firms are also different from the equilibrium locations in Hotelling's location model. It is well known that in Hotelling's model the outside firms are always paired, whereas in the equilibria we find, this is not necessarily the case.

Third, we consider a more general setting in which the network externality can be different for different firms. We say that two firms are asymmetric if the network effect for the two firms is different. We provide a necessary and sufficient condition under which a subgame perfect Nash equilibrium exists for three firms. A subgame perfect equilibrium exists if the network effect is the same for two out of three firms, and the effect is sufficiently larger for the third firm. This explains the lack of equilibria for three symmetric firms.

Fourth, we provide an example of a subgame perfect Nash equilibrium in which, counter-intuitively, a firm with a larger network effect obtains a larger market share than a firm with a smaller network effect due to their locations.

Related literature Hotelling's model is primarily used to explain product differentiation or the lack thereof. The original result found by Hotelling (1929) is that in the case of a duopoly, firms want to locate in the middle of the market and minimize differentiation. Eaton and Lipsey (1975) assume that prices are fixed and extend the analysis to multiple firms and different market structures. They argue that firms have a tendency to create local clusters, and minimum differentiation is just a special case of a local cluster for two firms. The principle of minimum differentiation was criticized by d'Aspremont et al. (1979) by showing that no pure price equilibrium exists if locations are sufficiently close. They show that under quadratic transportation costs, firms want to maximize differentiation. Osborne and Pitchik (1987) characterize a mixed strategy pricing equilibrium for linear transportation costs in which firms have substantial differentiation.

Closest to ours is Kohlberg (1983) who introduces negative network externalities into Hotelling's location model. He shows that there are no equilibria in which all firms locate at different locations. Palma and Leruth (1989) consider a model in which firms first choose a capacity, and second, set a price. Their way of modelling congestion corresponds to our way of modelling externalities. Navon et al. (1995) focus on the pricing behavior of firms for fixed locations in the presence of negative or positive network externalities. Negative network effects tend to lessen competition and increase prices, whereas positive network effects make competition fiercer and lead to lower prices. A similar analysis and conclusion is given in Grilo et al. (2001) for quadratic instead of linear transportation costs. Ahlin and Ahlin (2013) consider a duopoly with strategic pricing and negative network externalities, and show that differentiation decreases with network effects. Lambertini and Orsini (2013) show that even in the presence of network externalities, switching costs can be used to eliminate the incentive to undercut prices such that the minimum differentiation principle is restored.

There are also models that consider fixed locations on a circle, like Salop (1979), and study price competition with network externalities. Navon et al. (1995) assume that transportation costs are linear, whereas Heikkinen (2014) assumes that transportation costs are quadratic. Friedman and Grilo (2005) consider a model with externalities, where each consumer's utility rises when similar con- 
sumers buy the same good and falls when sufficiently dissimilar consumers buy the good.

Other recent work on Hotelling's model considers graphs, see Pálvölgyi (2011), Fournier and Scarsini (2014), Fournier (2016), finite sets of locations, see Núñez and Scarsini (2016) and Núñez and Scarsini (2017), and optimal interval division, see Tian (2015).

The organization of this paper is as follows. Section 2 explains the basic model with linear network externalities and provides some preliminary results. In Sect. 3, we consider the model with symmetric firms. Section 4 generalizes the setting and allows firms to be asymmetric. Most of the proofs are relegated to the Appendix.

\section{Preliminary results}

\subsection{The model}

Let $N=\{1, \ldots, n\}$, where $n \geq 2$, be the set of firms. Each firm sells a homogeneous product for a fixed price. The goal of each firm is to maximize its market share. We assume that consumers are uniformly distributed on the interval $[0,1]$. Each consumer purchases one product. In order to do so, the consumer has to visit the location of one of the firms and incurs transportation costs. We normalize the cost of travel to one per unit distance. In addition, each consumer incurs waiting costs when visiting a firm depending on the amount of consumers that visit that firm. So the total costs for a consumer $z \in[0,1]$ of visiting firm $i \in N$ with location $x_{i} \in[0,1]$ and market share $s_{i} \in[0,1]$ are

$$
\left|x_{i}-z\right|+w_{i}\left(s_{i}\right)
$$

where $w_{i}:[0,1] \rightarrow \mathbb{R}_{+}$. We assume that each consumer chooses a firm so as to minimize his total costs. Kohlberg (1983) assumes that $w_{i}$ is the same strictly increasing continuous function for each firm $i \in N$. We assume that $w_{i}$ is linear. Moreover, we allow $w_{i} \neq w_{j}$ for some $i, j \in N$. An interpretation is that firms might have different speeds with which consumers are served.

The game proceeds in two stages. In the first stage, each firm $i$ simultaneously selects a location $x_{i}$. These simultaneous choices constitute a vector of locations $x=\left(x_{1}, \ldots, x_{n}\right)$ of the firms.

In the second stage, the consumers simultaneously choose a firm based on these locations. More formally, let $X=[0,1]^{n}$ denote the collection of all possible vectors of firm locations. A choice function is a measurable function $f: X \times[0,1] \rightarrow N$ that, for each consumer $z \in[0,1]$ and every vector $x \in X$ of locations, assigns firm $f(x, z)$ to consumer $z$. In other words, given the vector $x$ of locations of firms, consumer $z$ will visit firm $f(x, z)$ according to choice function $f$.

A strategy profile (of the firms and the consumers) is a pair $(x, f)$, where $x$ is a vector of locations and $f$ is a choice function.

Given a strategy profile $(x, f)$, the payoffs for the firms and the consumers are defined as follows. Define $f_{i}^{-1}(x)=\{z \in[0,1] \mid f(x, z)=i\}$ for all $i \in N$. 


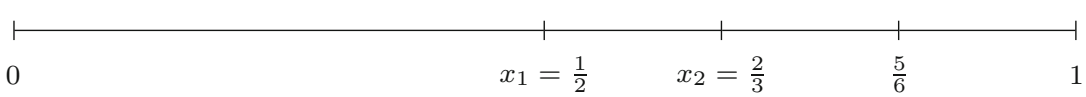

Fig. 1 An example of a Nash equilibrium which is not subgame perfect

Let $s_{i}(x, f)$ for all $i \in N$ be the Lebesgue measure of the set $f_{i}^{-1}(x)^{1}$ and define $s(x, f)=\left(s_{i}(x, f)\right)_{i \in N}$. We refer to $s_{i}(x, f)$ as the market share of firm $i$. The total costs for a consumer at location $z \in[0,1]$ of visiting firm $i \in N$ are

$$
C_{z, i}(x, f)=\left|x_{i}-z\right|+a_{i} \cdot s_{i}(x, f),
$$

where $a_{i} \in \mathbb{R}_{+}$is the latency coefficient of firm $i$. We say that firm $i \in N$ is less efficient than firm $j \in N$ if $a_{i}>a_{j}$. Each consumer seeks to minimize his total costs, while each firm aims to maximize his market share.

\subsection{Subgame perfect Nash equilibrium}

Since consumers are reacting to the locations chosen by the firms, the game played between firms and consumers involves an element of timing: first firms choose their locations, and subsequently consumers make decisions based on the locations chosen by the firms. Therefore we use subgame perfect Nash equilibrium as the natural solution concept.

Definition 1 A strategy profile $(x, f)$ is a subgame perfect Nash equilibrium (SPE) if the following two conditions are satisfied:

(i) for all $i \in N, s_{i}(x, f) \geq s_{i}\left(\left(x_{i}^{\prime}, x_{-i}\right), f\right)$ for all $x_{i}^{\prime} \in[0,1]$.

(ii) for all $x \in X$ and all $z \in[0,1], C_{z, f(x, z)}(x, f) \leq C_{z, i}(x, f)$ for all $i \in N$.

Kohlberg (1983) refers to the subgame perfect Nash equilibria of the game specified above as equilibria, or sometimes Cournot-Nash equilibria, because he only considers choice functions that minimize costs for each of the consumers for every possible vector of locations of the firms. Thus, in Kohlberg (1983), condition (ii) of our definition is hardwired into the model itself.

The following example motivates why we focus on subgame perfect Nash equilibrium and not merely on Nash equilibrium.

Example 1 Assume that $n=2, a_{1}=0$ and $a_{2}=1$.

Consider the following choice function. For all $x \in X$ and $z \in[0,1]$, define

$$
f(x, z)= \begin{cases}1 & \text { if } z \leq \frac{5}{6} \\ 2 & \text { otherwise }\end{cases}
$$

(see Fig. 1). Then $(x, f)$ is not an SPE, since condition (ii) in Definition 1 only holds for $x=\left(\frac{1}{2}, \frac{2}{3}\right)$. We will see in Lemma 3 that there is no choice function $f$ such that

\footnotetext{
1 The choice function $f$ is measurable, so the Lebesgue measure of $f_{i}^{-1}(x)$ is defined.
} 
$(x, f)$ is an SPE. However, notice that the strategy profile $(x, f)$ is a Nash equilibrium, neither the firms nor the consumers have an incentive to deviate unilaterally. In fact, we will see that for each $x \in X$ there is a choice function $f$ that minimizes costs for all users and thus, for each $x \in X$, there is a strategy profile that is a Nash equilibrium, by defining the choice function in a similar way as above.

The following result of Kohlberg (1983) is useful for the upcoming analysis. We omit the proof.

Lemma 1 (Kohlberg 1983) Let $a_{i}>0$ for all $i \in N$. For each vector of locations $x$, there are unique market shares $s(x, f)$ such that $C_{z, f(x, z)}(x, f) \leq C_{z, i}(x, f)$ for all $z \in[0,1]$ and all $i \in N$ for some choice function $f$.

Lemma 1 implies that each vector of locations has unique corresponding market shares. Notice that this does not imply that the corresponding cost minimizing choice function is unique. For example, if $n=2, a_{1}=a_{2}$ and $x_{1}=x_{2}$ then every choice function that yields a partition of $[0,1]$ such that both firms have a market share of $1 / 2$ minimizes costs for consumers.

\subsection{Properties of SPE}

In this section we derive a few properties of SPE that are useful in the analysis in the remainder of this paper. The next result follows from the costs minimization of the consumers.

Lemma 2 Given $x \in X$, let $f$ satisfy $C_{z, f(x, z)}(x, f) \leq C_{z, i}(x, f)$ for all $z \in[0,1]$ and all $i \in N$.

(a) If $x_{i}=x_{j}$ for some $i, j \in N$, then $C_{z, i}(x, f)=C_{z, j}(x, f)$ for all $z \in[0,1]$.

(b) If $x_{i}<x_{j}$ for some $i, j \in N$, then one of the following three statements is true.

(i) $C_{z, i}(x, f)=C_{z, j}(x, f)$ for all $z \in\left[0, x_{i}\right]$ and $C_{z, i}(x, f)>C_{z, j}(x, f)$ for all $z \in\left(x_{i}, 1\right]$.

(ii) $C_{z, i}(x, f)<C_{z, j}(x, f)$ for all $z \in\left[0, x_{j}\right)$ and $C_{z, i}(x, f)=C_{z, j}(x, f)$ for all $z \in\left[x_{j}, 1\right]$.

(iii) There is some $y \in\left(x_{i}, x_{j}\right)$ such that $C_{z, i}(x, f)<C_{z, j}(x, f)$ for all $z \in[0, y)$, $C_{y, i}(x, f)=C_{y, j}(x, f)$ and $C_{z, i}(x, f)>C_{z, j}(x, f)$ for all $z \in(y, 1]$.

Proof See Appendix.

Given $x \in X$, the above Lemma implies, among other things, that, even though there may not be a unique choice function that minimizes costs for consumers, there is a unique cost minimizing choice function $f_{x}^{*}$ that assigns intervals of consumers to firm locations in a monotonic way. That is, if firm $i$ is located to the left of firm $j$, then the interval of consumers assigned to firm $i$ is to the left of the interval of consumers assigned to firm $j$.

The choice function $f_{x}^{*}$ is constructed as follows. Let the profile of firm locations $x \in X$ be given. Take a permutation $\sigma$ of the firms such that $x_{\sigma(1)} \leq \cdots \leq x_{\sigma(n)}$. Define $z_{0}(x)=0$ and $z_{\sigma(i)}(x)=\sum_{j=1}^{i} s_{\sigma(j)}(x, f)$ for some cost minimizing choice function 
$f$ and all $i \in N$. We define choice function $f_{x}^{*}$ by $f_{x, \sigma(i)}^{*-1}(x)=\left[z_{\sigma(i-1)}(x), z_{\sigma(i)}(x)\right)$ for all $i \in N$ and all $x \in X$, and $f_{x}^{*}(x, 1)=\sigma(n)$.

Next we argue that Lemma 2 implies that if $(x, f)$ is an SPE, then $\left(x, f_{x}^{*}\right)$ is also an SPE. Let $(x, f)$ be an SPE. Suppose we have a choice function $f$ that yields a partition such that there are two subintervals of consumers $\left[a_{1}, b_{1}\right)$ and $\left[a_{2}, b_{2}\right)$ with $b_{1} \leq a_{2}$, so that the consumers in $\left[a_{1}, b_{1}\right)$ visit firm $i$ and the consumers in $\left[a_{2}, b_{2}\right)$ visit firm $j$ with $i>j$. For simplicity, assume that $b_{1}-a_{1}=b_{2}-a_{2}$. By Lemma 2 , the consumers in $\left[a_{1}, b_{1}\right)$ and the consumers in $\left[a_{2}, b_{2}\right)$ are indifferent between visiting firm $i$ or $j$ [case (a), (b)(i), or (b)(ii) of Lemma 2 applies]. So the choice function $f^{\prime}$ that assigns consumers $\left[a_{1}, b_{1}\right)$ to firm $j$, consumers $\left[a_{2}, b_{2}\right)$ to firm $i$, and all other consumers to the same firm as in $f$, is also an SPE. If we continue this process we end up with $f_{x}^{*}$.

Since we are merely interested in existence of SPE, we only consider the choice function $f_{x}^{*}$ (essentially we are back to the setting in Kohlberg 1983). For simplification, we write $x$ instead of $\left(x, f_{x}^{*}\right)$ in the remainder of this paper. We define $s(x), z(x)$ and $C_{z, i}(x)$ for all $x \in X$, all $z \in[0,1]$ and all $i \in N$ as before.

Let $x$ be an SPE. Without loss of generality assume that $x_{1} \leq \cdots \leq x_{n}$. In order to find the market share $s_{i}(x)$ of each firm $i \in N$, we have to solve the following system of equations which by Lemma 1 has a unique solution. Recall that $z_{i}(x)=\sum_{j=1}^{i} s_{j}(x)$. For $i=1, \ldots, n-1$,

$$
\left|x_{i}-z_{i}(x)\right|+a_{i} \cdot s_{i}(x)=\left|x_{i+1}-z_{i}(x)\right|+a_{i+1} \cdot s_{i+1}(x),
$$

and $\sum_{i=1}^{n} s_{i}(x)=1$. The next result states some characteristics of subgame perfect Nash equilibria.

Lemma 3 Let $x$ be an SPE. Then:

(i) $s_{i}(x)>0$ for all $i \in N$.

(ii) $x_{i} \in\left[z_{i-1}(x), z_{i}(x)\right]$.

(iii) $x_{1}=s_{1}(x)$ and $x_{n}=1-s_{n-1}(x)$.

(iv) $\left|\left\{i \in N \mid x_{i}=y\right\}\right| \leq 2$ for all $y \in[0,1]$.

(v) if $x_{i}=x_{j}$ for some $i, j \in N$, then $a_{i}=a_{j}$.

Proof See Appendix.

\section{Symmetric firms}

Assume that all firms have an equal latency coefficient, i.e. $a_{i}=a$ for all $i \in N$. If $a=0$ this is Hotelling's location model and if $a>0$ this is a special case of Kohlberg's model.

For $a=0$, Eaton and Lipsey (1975) prove the following results. We omit the proofs.

Theorem 1 (Eaton and Lipsey 1975) Let $a=0$.

(a) For $n=2,4,5$, there is a unique SPE.

(b) For $n=3$, there is no SPE. 
(c) For $n \geq 6$, there is an infinite number of SPEs.

For $a>0$, Kohlberg (1982) proves the following result.

Theorem 2 (Kohlberg 1982) Let $a>0$ and $n>2$. There is no SPE in which $x_{1}<$ $\ldots<x_{n}, z_{1}(x)=x_{1}, z_{i}(x) \in\left(x_{i}, x_{i+1}\right)$ for all $1<i<n-1$ and $z_{n-1}(x)=x_{n}$.

Proof See Appendix.

However, Kohlberg (1982) states that the nonexistence result is more general by claiming that in an SPE all the firm locations must be different. We provide examples with $n \in\{4,6\}$ and $a$ sufficiently large for which an SPE exists, and in which two firms choose the same location. For $n \in\{3,5\}$ the claim is valid as there are no SPEs.

\subsection{Even number of firms}

\subsubsection{Two firms}

Assume that $n=2$ and $a>0$. The following theorem is due to Kohlberg (1983). We omit the proof.

Theorem 3 (Kohlberg 1983) An SPE exists for all $a>0$. The SPE is given by $x=\left(\frac{1}{2}, \frac{1}{2}\right)$ and $s(x)=\left(\frac{1}{2}, \frac{1}{2}\right)$.

\subsubsection{Four firms}

Assume that $n=4$ and $a>0$.

Theorem 4 An SPE exists if and only if $a \geq 2 \cdot(2+\sqrt{5}) .^{2}$ If an SPE exists, it is given by

$$
x=\left(\frac{1+a}{2+4 a}, \frac{1}{2}, \frac{1}{2}, \frac{1+3 a}{2+4 a}\right) \text { and } s(x)=\left(\frac{1+a}{2+4 a}, \frac{a}{2+4 a}, \frac{a}{2+4 a}, \frac{1+a}{2+4 a}\right) .
$$

Proof See Appendix.

Remark 1 Even though firms are symmetric, their market shares need not be equal.

Example 2 Let $x$ be an SPE. By Theorem 4, we have that $x \rightarrow\left(\frac{1}{4}, \frac{1}{2}, \frac{1}{2}, \frac{3}{4}\right)$ as $a \rightarrow \infty$ (see Fig. 2). The locations of the firms differ from the equilibrium locations for four firms found by Eaton and Lipsey (1975).

\subsubsection{Six firms}

Assume that $n=6$ and $a>0$.

$2 a$ satisfies the inequality $a^{2}-8 a-4 \geq 0$. 


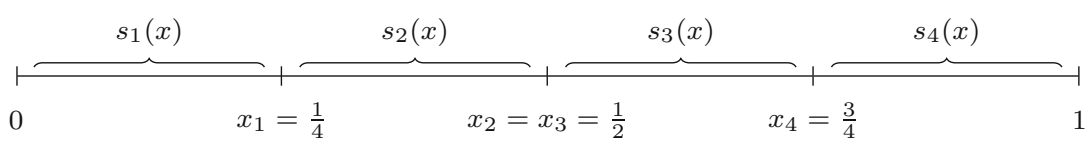

Fig. 2 Outcome of the SPE for four symmetric firms as $a \rightarrow \infty$

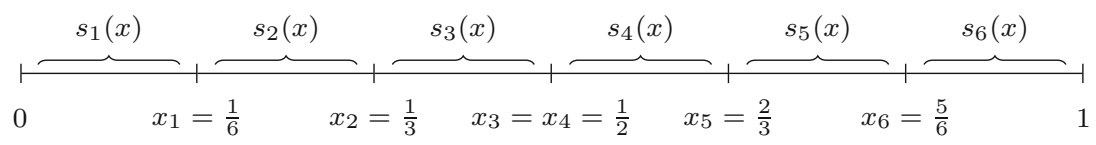

Fig. 3 Outcome of the SPE for six symmetric firms as $a \rightarrow \infty$

Theorem 5 An SPE exists if and only if $a \geq 29.8873 .{ }^{3}$ If an SPE exists, it is given by

$$
\begin{aligned}
x & =\left(\frac{1+2 a+a^{2}}{2+6 a+6 a^{2}}, \frac{1+3 a+2 a^{2}}{2+6 a+6 a^{2}}, \frac{1}{2}, \frac{1}{2}, \frac{1+3 a+4 a^{2}}{2+6 a+6 a^{2}}, \frac{1+4 a+5 a^{2}}{2+6 a+6 a^{2}}\right) \text { and } \\
s(x) & =\left(\frac{1+2 a+a^{2}}{2+6 a+6 a^{2}}, \frac{a+a^{2}}{2+6 a+6 a^{2}}, \frac{a^{2}}{2+6 a+6 a^{2}}, \frac{a^{2}}{2+6 a+6 a^{2}}, \frac{a+a^{2}}{2+6 a+6 a^{2}}, \frac{1+2 a+a^{2}}{2+6 a+6 a^{2}}\right) .
\end{aligned}
$$

Proof See Appendix.

Example 3 Let $x$ be an SPE. By Theorem 5, we have that $x \rightarrow\left(\frac{1}{6}, \frac{1}{3}, \frac{1}{2}, \frac{1}{2}, \frac{2}{3}, \frac{5}{6}\right)$ as $a \rightarrow \infty$ (see Fig. 3). The locations of the firms differ from the equilibrium locations for six firms found by Eaton and Lipsey (1975).

\subsection{Odd number of firms}

\subsubsection{Three firms}

Assume that $n=3$. The following result is due to Kohlberg (1983). We omit the proof.

Theorem 6 (Kohlberg 1983) For all a $>$ 0, there is no SPE.

\subsubsection{Five firms}

Assume that $n=5$.

Theorem 7 For all $a>0$, there is no SPE.

Proof See Appendix.

\subsection{Discussion}

We have seen that in the symmetric setting there is a unique subgame perfect equilibrium for two firms, independent of the value of $a$, and that there is no subgame

$3 a$ satisfies the inequality $a^{4}-27 a^{3}-84 a^{2}-68 a-16 \geq 0$. 
perfect equilibrium for three firms, also independent of the value of $a$. These results are in line with the results of Hotelling's location model. However, for more than three firms, we have either discovered new equilibrium locations (for four and six firms) or no equilibria at all (for five firms). Particularly, the existence of SPEs for four and six firms is surprising, showing that the claim of Kohlberg, that all the firm locations must be different, is incorrect (see Figs. 2, 3).

Our results suggest that an SPE exists if and only if the number of firms is even and the latency coefficient sufficiently large, but we have not been able to find a proof. Therefore we state the following conjecture.

Conjecture 1 Let $a_{i}=a$ for all $i \in N$. An SPE exists if and only if $n=2 k$ for some $k \in \mathbb{N}$ and $a$ is sufficiently high. The SPE is unique and given by $x_{i}=1-x_{2 k+1-i}=\frac{(1+a)^{k}}{2\left((1+a)^{k}-a^{k}\right)} \cdot\left(1-\left(\frac{a}{1+a}\right)^{i}\right)$ and $s_{i}(x)=s_{2 k+1-i}(x)=$ $\frac{a^{i-1} \cdot(1+a)^{k-i}}{2\left((1+a)^{k}-a^{k}\right)}$ for all $i \in\{1, \ldots, k\}$.

\section{Asymmetric firms}

In this section, we relax the assumption that all firms have an equal latency coefficient. Recall that this setting is not considered by Kohlberg (1983), because he assumes that firms are symmetric.

\subsection{Two firms}

Assume that $n=2$.

Theorem 8 An SPE exists if and only if $a_{1}=a_{2}$.

Proof Suppose that an SPE exists. Let $x$ be an SPE. Then by Lemma 3 (iii), $x_{1}=$ $s_{1}(x)$ and $x_{2}=1-s_{2}(x)$. Since $s_{1}(x)+s_{2}(x)=1$, we have $x_{1}=x_{2}$ and thus by Lemma 3 (iv), $a_{1}=a_{2}$.

Suppose that $a_{1}=a_{2}$. By Theorem 3, $x=\left(\frac{1}{2}, \frac{1}{2}\right)$ and $s(x)=\left(\frac{1}{2}, \frac{1}{2}\right)$ forms an SPE.

\subsubsection{Three firms}

Assume that $n=3$. The first lemma shows that, similar to what Kohlberg (1983) proves for symmetric firms, there is no SPE where all three firms choose a different location.

Lemma 4 Let $x$ be an SPE. Then $x_{1}=x_{2}$ or $x_{2}=x_{3}$.

Proof See Appendix.

The main result for three firms is as follows. 


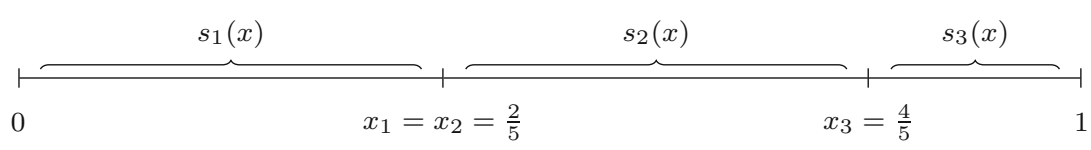

Fig. 4 Outcome of an SPE with three firms

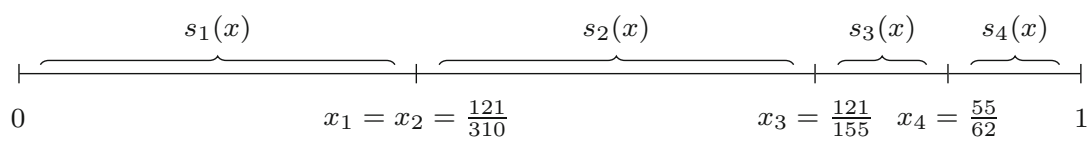

Fig. 5 SPE with four asymmetric firms

Theorem 9 An SPE exists if and only if (a) $a_{1}=a_{2}$ and $a_{3} \geq a_{2}+2$, or (b) $a_{2}=a_{3}$ and $a_{1} \geq a_{2}+2$.

For (a), the SPE is given by

$x=\left(\frac{a_{3}}{1+a_{2}+2 a_{3}}, \frac{a_{3}}{1+a_{2}+2 a_{3}}, \frac{2 a_{3}}{1+a_{2}+2 a_{3}}\right)$ and $s(x)=\left(\frac{a_{3}}{1+a_{2}+2 a_{3}}, \frac{a_{3}}{1+a_{2}+2 a_{3}}, \frac{1+a_{2}}{1+a_{2}+2 a_{3}}\right)$.

For (b), the SPE is given by

$x=\left(\frac{1+a_{2}}{1+2 a_{1}+a_{2}}, \frac{1+a_{1}+a_{2}}{1+2 a_{1}+a_{2}}, \frac{1+a_{1}+a_{2}}{1+2 a_{1}+a_{2}}\right)$ and $s(x)=\left(\frac{1+a_{2}}{1+2 a_{1}+a_{2}}, \frac{a_{1}}{1+2 a_{1}+a_{2}}, \frac{a_{1}}{1+2 a_{1}+a_{2}}\right)$.

Proof See Appendix.

Example 4 Assume that $a_{1}=a_{2}=0, a_{3}=2$ and let $x$ be an SPE. By Theorem 9, we have that $x=\left(\frac{2}{5}, \frac{2}{5}, \frac{4}{5}\right)$ (see Fig. 4$)$.

\subsection{Four firms}

Assume that $n=4$. The following example illustrates an equilibrium in which there is a less efficient firm that obtains a larger market share due to its location.

Example 5 Assume that $a_{1}=a_{2}=0, a_{3}=3 \frac{2}{3}$, and $a_{4}=4 \frac{2}{5}$. We claim that $x=\left(\frac{121}{310}, \frac{121}{310}, \frac{121}{155}, \frac{55}{62}\right)$ is an SPE (see Fig. 5). The locations of the firms are different from the locations found in Theorem 4. Also $s_{3}(x)=\frac{33}{310}<\frac{7}{62}=s_{4}(x)$.

In order to prove that $x$ is an SPE, it is sufficient to show that firm 2 does not want to deviate to the right, firm 3 does not want to deviate to the left nor to the right, and firm 4 does not want to deviate to the left.

Since market shares are piecewise linear in the location of firm 2, we show that firm 2 has no incentive to locate at $x_{2}^{\prime}=x_{3}: s_{2}\left(x_{2}^{\prime}, x_{-2}\right)=\frac{121}{310}$. Then we show that firm 2 has no incentive to locate at $x_{2}^{\prime \prime}=x_{4}: s_{2}\left(x_{2}^{\prime \prime}, x_{-2}\right)=\frac{103}{310}$. Since $1-\frac{103}{310}<\frac{55}{62}$, there is also no incentive to locate as rightmost firm.

Observe that firm 3 could only improve by being the leftmost or rightmost firm. Suppose firm 3 locates as leftmost firm at $x_{3}^{\prime}=s_{3}\left(x_{3}^{\prime}, x_{-3}\right)$. Then $s_{3}\left(x_{3}^{\prime}, x_{-3}\right)=\frac{363}{4340}$. Suppose firm 3 locates as rightmost firm at $x_{3}^{\prime \prime}=1-s_{3}\left(x_{3}^{\prime \prime}, x_{-3}\right)$. Then $s_{3}\left(x_{3}^{\prime \prime}, x_{-3}\right)=$ 
$\frac{2268}{22475}$. Since $s_{3}\left(x_{3}^{\prime}, x_{-3}\right)<s_{3}(x)$ and $s_{3}\left(x_{-3}, x_{3}^{\prime \prime}\right)<s_{3}(x)$, firm 3 has no incentive to deviate.

Observe that firm 4 could only improve by being the leftmost firm. Suppose firm 4 locates as leftmost firm at $x_{4}^{\prime}=s_{4}\left(x_{4}^{\prime}, x_{-4}\right)$. Then $s_{4}\left(x_{4}^{\prime}, x_{-4}\right)=\frac{121}{1674}$. Since $s_{4}\left(x_{4}^{\prime}, x_{-4}\right)<s_{4}(x)$, firm 4 has no incentive to deviate.

\subsection{Discussion}

The examples for three and four firms show that the set of equilibria increases if we allow for asymmetries between the firms. Moreover, these new equilibria bear surprising features, for example, a less efficient firm might have a larger market share due to its location (see Example 5), that do not exist in the symmetric setting. However, a full characterization of these equilibria remains an open question.

Acknowledgements We would like to thank the associate editor and an anonymous referee for detailed comments and useful suggestions. Financial support from the Graduate School of Business and Economics, Maastricht University, is gratefully acknowledged.

\section{Appendix}

\section{Proof (Lemma 2)}

(a) Assume that $x_{i}=x_{j}$ for some $i, j \in N$. Since $\left|x_{i}-z\right|=\left|x_{j}-z\right|$ for all $z \in[0,1]$, we can focus on the waiting costs. If $a_{i} \cdot s_{i}(x, f)<a_{j} \cdot s_{j}(x, f)$, then a consumer $z$ with $f(x, z)=j$ could decrease his total costs by visiting firm $i$. Similar for the reverse inequality. Hence $C_{z, i}(x, f)=\left|x_{i}-z\right|+a_{i} \cdot s_{i}(x, f)=$ $\left|x_{j}-z\right|+a_{j} \cdot s_{j}(x, f)=C_{z, j}(x, f)$.

(b) Assume that $x_{i}<x_{j}$ for some $i, j \in N$.

(i) Suppose that $C_{0, i}(x, f)=C_{0, j}(x, f)$. If $z \in\left[0, x_{i}\right]$, then by assumption, $C_{z, i}(x, f)=x_{i}-z+a_{i} \cdot s_{i}(x, f)=x_{j}-z+a_{j} \cdot s_{j}(x, f)=C_{z, j}(x, f)$.

If $z \in\left(x_{i}, x_{j}\right]$, then

$$
\begin{aligned}
C_{z, i}(x, f) & =z-x_{i}+a_{i} \cdot s_{i}(x, f)>x_{i}-z+a_{i} \cdot s_{i}(x, f) \\
& =x_{j}-z+a_{j} \cdot s_{j}(x, f)=C_{z, j}(x, f),
\end{aligned}
$$

where the inequality follows from $x_{i}<z$ and the equality by assumption.

If $z \in\left(x_{j}, 1\right]$, then

$$
\begin{aligned}
C_{z, i}(x, f) & =z-x_{i}+a_{i} \cdot s_{i}(x, f)=z-x_{j}+x_{j}-x_{i}+a_{i} \cdot s_{i}(x, f) \\
& >z-x_{j}+x_{i}-x_{j}+a_{i} \cdot s_{i}(x, f)=z-x_{j}+a_{j} \cdot s_{j}(x, f)=C_{z, j}(x, f),
\end{aligned}
$$

where the inequality follows from $x_{i}<x_{j}$ and the third equality by assumption.

(ii) Suppose that $C_{1, i}(x, f)=C_{1, j}(x, f)$. Then, by symmetry of the problem, a similar argument as for (i) holds. 
(iii) By (i) and (ii), we can suppose that $x_{i}<x_{j}, C_{0, i}(x, f) \neq C_{0, j}(x, f)$ and $C_{1, i}(x, f) \neq C_{1, j}(x, f)$. Suppose $C_{0, i}(x, f)>C_{0, j}(x, f)$. By (i), we have $C_{z, i}(x, f)>C_{z, j}(x, f)$ for all $z \in[0,1]$. By condition (ii) of Definition 1 , this implies that $s_{i}(x)=0$. However, this means that $C_{0, i}(x, f)<C_{0, j}(x, f)$, which contradicts the assumption. By symmetry, a similar argument holds if $C_{1, i}(x, f)<C_{1, j}(x, f)$.

So suppose that $C_{0, i}(x, f)<C_{0, j}(x, f)$ and $C_{1, i}(x, f)>C_{1, j}(x, f)$. This implies that $C_{x_{i}, i}(x, f)<C_{x_{i}, j}(x, f)$ and $C_{x_{j}, i}(x, f)>C_{x_{j}, j}(x, f)$. But then there is $y \in\left(x_{i}, x_{j}\right)$ with $C_{y, i}(x, f)=C_{y, j}(x, f)$.

Proof (Lemma 3) (i) Suppose that $s_{i}(x)=0$ for some $i \in N$. We show that firm $i$ can increase its market share by a unilateral deviation. Let $x_{i}^{\prime}$ be such that $\left|\left\{i \in N \mid x_{i}=x_{i}^{\prime}\right\}\right|=0$. Since the transportation costs for consumer $x_{i}^{\prime}$ are zero and $\left|\left\{i \in N \mid x_{i}=x_{i}^{\prime}\right\}\right|=0$, we must have $s_{i}\left(x_{i}^{\prime}, x_{-i}\right)>0$. This however contradicts condition (i) in Definition 1.

(ii) Suppose that $x_{i} \notin\left[z_{i-1}(x), z_{i}(x)\right]$ for some $i \in N$. We show that firm $i$ can increase its market share by a unilateral deviation. See the figure below. If multiple firms are located at $x_{i}$, we consider the firm with the lowest number.

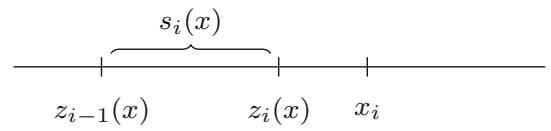

Since $x$ is an SPE, we have $C_{z_{i-1}(x), i-1}(x)=C_{z_{i-1}(x), i}(x)$ if $i>1$ and $C_{z_{i}(x), i}(x)=$ $C_{z_{i}(x), i+1}(x)$. If firm $i$ locates at $x_{i}^{\prime}$, with $z_{i}(x)<x_{i}^{\prime}<x_{i}$, then the transportation costs for each consumer $z \in\left[z_{i-1}(x), z_{i}(x)\right]$ decrease. So in order to offset the decrease in transportation costs, there must be an increase in the market share of firm $i$. This however contradicts condition (i) in Definition 1.

(iii) We show that $x_{1}=s_{1}(x)$. Symmetry of the problem implies $x_{n}=1-s_{n-1}(x)$.

Suppose that $x_{1} \neq s_{1}(x)$. We show that firm 1 can increase its market share by a unilateral deviation. By (ii), we have that $x_{1}<s_{1}(x) \leq x_{2}$. If firm 1 locates at $x_{1}^{\prime}$, with $x_{1}<x_{1}^{\prime}<s_{1}(x)$, we observe from $C_{s_{1}(x), 1}(x)=C_{s_{1}(x), 2}(x)$ that $s_{1}(x)-x_{1}^{\prime}+$ $a_{1} \cdot s_{1}(x)<x_{2}-s_{1}(x)+a_{2} \cdot s_{2}(x)$. So in order to offset the decrease in transportation costs, there must be an increase in the market share of firm 1 . This however contradicts condition (i) in Definition 1.

(iv) We show that $\left|\left\{i \in N \mid x_{i}=x\right\}\right| \leq 2$ for all $x \in[0,1]$. Suppose $\left|\left\{i \in N \mid x_{i}=x\right\}\right|>2$ for some $x \in[0,1]$. We derive a contradiction. Since $s_{i}(x)>0$ for all $i \in N$, there is a firm $i \in\left\{i \in N \mid x_{i}=x\right\}$ such that $x_{i} \notin\left[z_{i-1}(x), z_{i}(x)\right]$. This however contradicts (ii).

(v) Assume that $x_{i}=x_{j}$ for some $i, j \in N$. Suppose $a_{i}<a_{j}$. We derive a contradiction. Define $x^{\prime}=\left(x_{1}, \ldots, x_{i+1}, x_{i}, \ldots, x_{n}\right)$. We obtain the following result.

Claim $x$ is an SPE if and only if $x^{\prime}$ is an SPE.

Proof Suppose $x$ is an SPE. By Lemma 2 (i), we have $C_{z, i}(x)=C_{z, i+1}(x)$ for all $z \in[0,1]$. So in particular for all $z \in\left[z_{i-1}(x), z_{i+1}(x)\right]$. Consider the following choice function 


$$
f\left(x^{\prime}, z\right)= \begin{cases}i+1 & \text { if } z \in\left[z_{i-1}(x), z_{i-1}(x)+s_{i+1}(x)\right] \\ i & \text { if } z \in\left[z_{i-1}(x)+s_{i+1}(x), z_{i+1}(x)\right] \\ f(x, z) & \text { if } z \in\left[0, z_{i-1}(x)\right) \text { or } z \in\left(z_{i+1}(x), 1\right] .\end{cases}
$$

So the consumers visiting firm $i+1$ are on the left of the consumers visiting firm $i$. Note that $s_{i}\left(x^{\prime}\right)=s_{i}(x)$ and $s_{i+1}\left(x^{\prime}\right)=s_{i+1}(x)$ and so $C_{z, i}\left(x^{\prime}\right)=C_{z, i+1}\left(x^{\prime}\right)$ for all $z \in\left[z_{i-1}(x), z_{i+1}(x)\right]$. Since $x$ is an SPE, $x^{\prime}$ is also an SPE.

Since the converse implication can be proven analogously, this completes the proof of the Claim.

Since $x_{i}=x_{i+1}$, we have $a_{i} \cdot s_{i}(x)=a_{i+1} \cdot s_{i+1}(x)$ and thus by assumption $s_{i}(x)>s_{i+1}(x)$. We also have $x_{i+1}=z_{i}(x)=z_{i-1}(x)+s_{i}(x)>z_{i-1}(x)+s_{i+1}(x)$, where the first equality follows from (ii). But then (ii) implies that $x^{\prime}$ is not an SPE (see the figure below). Hence, by the above Claim, $x$ is no SPE, which is a contradiction.

\begin{tabular}{|c|c|c|}
\hline$s_{i}($ & \multicolumn{2}{|c|}{$s_{i+1}(x)$} \\
\hline$z_{i-1}(x)$ & $x_{i}=x_{i+1}$ & $z_{i+1}(x)$ \\
\hline$s_{i+1}(x)$ & $s_{i}(x)$ & \\
\hline$z_{i-1}(x)$ & $x_{i+1}=x_{i}$ & $z_{i+1}(x)$ \\
\hline
\end{tabular}

Proof (Theorem 2) The proof below follows the same lines as the proof in Kohlberg (1982). Let $x$ be an SPE with $x_{1}<\cdots<x_{n}, z_{1}(x)=x_{1}, z_{i}(x) \in\left(x_{i}, x_{i+1}\right)$ for all $1<i<n-1$ and $z_{n-1}(x)=x_{n}$. Let $k \in N$ with $1<k<n$.

Let $s_{i}^{L}, s_{i}^{R}, z_{i}^{L}$ and $z_{i}^{R}$ for all $i \in N$ denote the left and right partial derivative of $s_{i}(x)$ and $z_{i}(x)$, respectively, with respect to $x_{k}$.

We will prove by induction that $\frac{s_{i}^{L}}{z_{i}^{L}}<\frac{s_{i}^{R}}{z_{i}^{R}}$ for all $1<i<k$. If firm $k$ locates marginally to the left, then by taking the derivative of the equation for firm 1 and 2 , see Eq. (1), we get

$$
-z_{1}^{L}+a \cdot s_{1}^{L}=-z_{1}^{L}+a \cdot s_{2}^{L} .
$$

If firm $k$ locates marginally to the right, then we get

$$
z_{1}^{R}+a \cdot s_{1}^{R}=-z_{1}^{R}+a \cdot s_{2}^{R}
$$

Since $s_{1}^{L}=z_{1}^{L}$ and $s_{1}^{R}=z_{1}^{R}$, we have

$$
\frac{s_{2}^{L}}{z_{1}^{L}}=1<1+2 / a=\frac{s_{2}^{R}}{z_{1}^{R}},
$$


and since $z_{2}^{L}=z_{1}^{L}+s_{2}^{L}$ and $z_{2}^{R}=z_{1}^{R}+s_{2}^{R}$, we conclude that

$$
\frac{s_{2}^{L}}{z_{2}^{L}}=\frac{1}{\left(\frac{s_{2}^{L}}{z_{1}^{L}}\right)^{-1}+1}<\frac{1}{\left(\frac{s_{2}^{R}}{z_{1}^{R}}\right)^{-1}+1}=\frac{s_{2}^{R}}{z_{2}^{R}} .
$$

Now suppose that $\frac{s_{i}^{L}}{z_{i}^{L}}<\frac{s_{i}^{R}}{z_{i}^{R}}$ for all $i$ with $1<i<k-1$, we show that the inequality also holds for firm $i+1$. If firm $k$ locates marginally to the left, we get

$$
z_{i}^{L}+a \cdot s_{i}^{L}=-z_{i}^{L}+a \cdot s_{i+1}^{L} .
$$

If firm $k$ locates marginally to the right, we get

$$
z_{i}^{R}+a \cdot s_{i}^{R}=-z_{i}^{R}+a \cdot s_{i+1}^{R} .
$$

Since

$$
\frac{s_{i+1}^{L}}{z_{i}^{L}}=\frac{s_{i}^{L}}{z_{i}^{L}}+2 / a,
$$

and

$$
\frac{s_{i+1}^{R}}{z_{i}^{R}}=\frac{s_{i}^{R}}{z_{i}^{R}}+2 / a,
$$

we conclude that

$$
\begin{aligned}
\frac{s_{i+1}^{L}}{z_{i+1}^{L}} & =\frac{1}{\left(\frac{s_{i+1}^{L}}{z_{i}^{L}}\right)^{-1}+1}=\frac{1}{\left(\frac{s_{i}^{L}}{z_{i}^{L}}+2 / a\right)^{-1}+1} \\
& <\frac{1}{\left(\frac{s_{i}^{R}}{z_{i}^{R}}+2 / a\right)^{-1}+1}=\frac{1}{\left(\frac{s_{i+1}^{R}}{z_{i}^{R}}\right)^{-1}+1}=\frac{s_{i+1}^{R}}{z_{i+1}^{R}}
\end{aligned}
$$

where the first equality follows from $z_{i+1}^{L}=z_{i}^{L}+s_{i+1}^{L}$, the inequality from the induction hypothesis, and the last equality from $z_{i+1}^{R}=z_{i}^{R}+s_{i+1}^{R}$.

Moreover $\frac{s_{i}^{L}}{z_{i}^{L}}>0$ for all $1<i<k$ as both $s_{i}$ and $z_{i}$ decrease once firm $k$ moves marginally to the left.

By symmetry we obtain that $0<\frac{s_{i}^{R}}{-z_{i-1}^{R}}<\frac{s_{i}^{L}}{-z_{i-1}^{L}}$ for all $k<i<n$.

Also, if firm $k$ moves marginally to the left, then by taking the derivative of the equation for firm $k-1$ and $k$, see Eq. (1), we get

$$
z_{k-1}^{L}+a \cdot s_{k-1}^{L}=1-z_{k-1}^{L}+a \cdot s_{k}^{L},
$$


and for firm $k$ and $k+1$, see Eq. (1), we get

$$
z_{k}^{L}-1+a \cdot s_{k}^{L}=-z_{k}^{L}+a \cdot s_{k+1}^{L} \text {. }
$$

Adding these two equations, and using that $z_{k}^{L}-z_{k-1}^{L}=s_{k}^{L}$ and that in equilibrium $s_{k}^{L} \geq 0$ yields

$$
a \cdot s_{k-1}^{L}+a \cdot s_{k+1}^{L}=(2+2 a) \cdot s_{k}^{L} \geq 0 .
$$

Dividing by $z_{k-1}^{L}>0$ and using that $z_{k-1}^{L} \geq z_{k}^{L}$ and $s_{k+1}^{L} \leq 0$ yields

$$
a \cdot \frac{s_{k-1}^{L}}{z_{k-1}^{L}}+a \cdot \frac{s_{k+1}^{L}}{z_{k}^{L}} \geq 0,
$$

and thus

$$
\frac{s_{k-1}^{L}}{z_{k-1}^{L}} \geq \frac{s_{k+1}^{L}}{-z_{k}^{L}} .
$$

By symmetry we obtain that

$$
\frac{s_{k-1}^{R}}{z_{k-1}^{R}} \leq \frac{s_{k+1}^{R}}{-z_{k}^{R}} .
$$

Combining all these inequalities yields

$$
\frac{s_{k-1}^{L}}{z_{k-1}^{L}}<\frac{s_{k-1}^{R}}{z_{k-1}^{R}} \leq \frac{s_{k+1}^{R}}{-z_{k}^{R}}<\frac{s_{k+1}^{L}}{-z_{k}^{L}} \leq \frac{s_{k-1}^{L}}{z_{k-1}^{L}} .
$$

Hence we obtained a contradiction and can conclude that there is no SPE in which $x_{1}<\cdots<x_{n}, z_{1}(x)=x_{1}, z_{i}(x) \in\left(x_{i}, x_{i+1}\right)$ for all $1<i<n-1$ and $z_{n-1}(x)=x_{n}$.

Proof (Theorem 4) By Lemma 3 (iv) and symmetry, we distinguish the following four cases.

(1) Assume that $x_{1}=x_{2}<x_{3}=x_{4}$. By Lemma 3 (iii), we obtain the figure below.

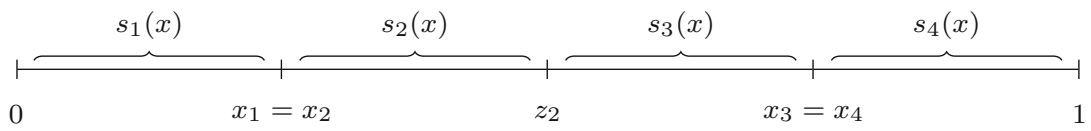

Solving the equalities corresponding to the above figure

$$
\begin{aligned}
a \cdot s_{1}(x) & =a \cdot s_{2}(x) \\
s_{2}(x)+a \cdot s_{2}(x) & =s_{3}(x)+a \cdot s_{3}(x)
\end{aligned}
$$




$$
a \cdot s_{3}(x)=a \cdot\left(1-z_{3}(x)\right),
$$

yields $s(x)=\left(\frac{1}{4}, \frac{1}{4}, \frac{1}{4}, \frac{1}{4}\right)$ and thus $x=\left(\frac{1}{4}, \frac{1}{4}, \frac{3}{4}, \frac{3}{4}\right)$. Suppose firm 2 locates at $x_{2}^{\prime}=\frac{1}{2}$. Solving

$$
\begin{aligned}
s_{1}\left(x_{2}^{\prime}, x_{-2}\right)-\frac{1}{4}+a \cdot s_{1}\left(x_{2}^{\prime}, x_{-2}\right) & =\frac{1}{2}-s_{1}\left(x_{2}^{\prime}, x_{-2}\right)+a \cdot s_{2}\left(x_{2}^{\prime}, x_{-2}\right) \\
z_{2}\left(x_{2}^{\prime}, x_{-2}\right)-\frac{1}{2}+a \cdot s_{2}\left(x_{2}^{\prime}, x_{-2}\right) & =\frac{3}{4}-z_{2}\left(x_{2}^{\prime}, x_{-2}\right)+a \cdot s_{3}\left(x_{2}^{\prime}, x_{-2}\right) \\
a \cdot s_{3}\left(x_{2}^{\prime}, x_{-2}\right) & =a \cdot\left(1-z_{3}\left(x_{2}^{\prime}, x_{-2}\right)\right)
\end{aligned}
$$

yields

$$
s_{2}\left(x_{2}^{\prime}, x_{-2}\right)=\frac{8+15 a+4 a^{2}}{8 \cdot\left(4+7 a+2 a^{2}\right)} .
$$

For this deviation to be unprofitable, we must have $a=0$. This contradicts the assumption that $a>0$.

(2) Assume that $x_{1}<x_{2}=x_{3}<x_{4}$. By Lemma 3 (ii) and (iii), we obtain the figure below.

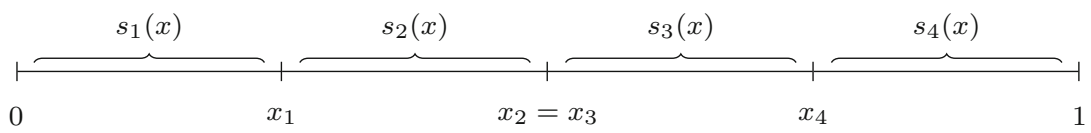

Solving the equalities corresponding to the above figure yields $s(x)=$ $\left(\frac{1+a}{2+4 a}, \frac{a}{2+4 a}, \frac{a}{2+4 a}, \frac{1+a}{2+4 a}\right)$ and thus $x=\left(\frac{1+a}{2+4 a}, \frac{1}{2}, \frac{1}{2}, \frac{1+3 a}{2+4 a}\right)$. Suppose firm 2 locates as leftmost firm at $x_{2}^{\prime}=s_{2}\left(x_{2}^{\prime}, x_{-2}\right)$. Then

$$
s_{2}\left(x_{2}^{\prime}, x_{-2}\right)=\frac{(2+a) \cdot\left(2+3 a+2 a^{2}\right)}{2 \cdot\left(4+16 a+17 a^{2}+4 a^{3}\right)} .
$$

For this deviation to be unprofitable, we must have $a \geq 2 \cdot(2+\sqrt{5})$.

To prove that the strategy profile is an SPE, it is sufficient to check that firm 1 does not want to deviate to the right and firm 2 does not want to deviate to the left.

By Lemma 3 (iii), firm 1 has no incentive to deviate in between $x_{1}$ and $x_{2}$. By symmetry and since there is an additional firm at $x_{4}$, firm 1 has also no incentive to deviate to the right of $\frac{1}{2}$.

Since market shares are piecewise linear in the location of firm 2, we show that firm 2 has no incentive to locate at $x_{2}^{\prime}=x_{1}$ :

$$
s_{2}\left(x_{2}^{\prime}, x_{-2}\right)=\frac{(2+a) \cdot\left(2+5 a+4 a^{2}\right)}{4 \cdot(1+2 a) \cdot\left(4+7 a+2 a^{2}\right)} .
$$


Since $s_{2}\left(x_{2}^{\prime}, x_{-2}\right)<s_{2}(x)$ if $a \geq 2 \cdot(2+\sqrt{5})$, firm 2 has no incentive to deviate. Since there is also no incentive to locate as leftmost firm, firm 2 has no profitable deviation.

(3) Assume that $x_{1}=x_{2}<x_{3}<x_{4}$. By Lemma 3 (ii) and (iv), we obtain the figure below. Note that you can show that there is no SPE with $z_{2}(x)<x_{3}$.

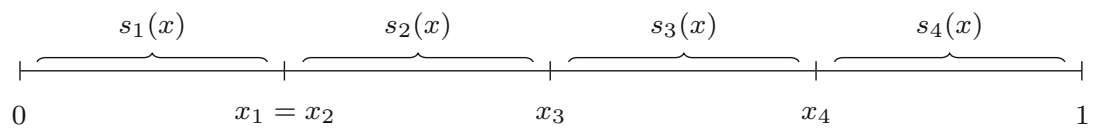

Solving the equalities corresponding to the above figure yields

$$
s_{2}(x)=\frac{a^{2}}{1+3 a+4 a^{2}} .
$$

Suppose firm 2 locates at $x_{2}^{\prime}=x_{3}$. Then

$$
s_{2}\left(x_{2}^{\prime}, x_{-2}\right)=\frac{a \cdot\left(4+7 a+4 a^{2}\right)}{2 \cdot(3+2 a) \cdot\left(1+3 a+4 a^{2}\right)} .
$$

For this deviation to be unprofitable, we must have $a=0$. This contradicts the assumption that $a>0$.

(4) Assume that $x_{1}<x_{2}<x_{3}<x_{4} \cdot{ }^{4}$ We show the proof if $x_{2}<z_{2}(x)<x_{3}$. Other cases, $z_{2}(x)=x_{2}$ and $z_{2}(x)=x_{3}$, can be solved analogously.

Assume $x_{2}<z_{2}(x)<x_{3}$. Solving the equalities yields

$$
s_{2}(x)=\frac{a^{2}+a^{3}-\left(1+2 a-a^{2}\right) \cdot x_{2}+\left(1+4 a+3 a^{2}\right) \cdot x_{3}}{2 \cdot(1+2 a) \cdot\left(1+3 a+a^{2}\right)} .
$$

Suppose firm 2 locates an arbitrary small $\epsilon>0$ to the right. For this deviation to be unprofitable, we must have $a=0$. This contradicts the assumption that $a>0$.

Proof (Theorem 5) By Lemma 3 (iv) and symmetry, we distinguish the following nine cases.

(1) Assume that $x_{1}=x_{2}<x_{3}=x_{4}<x_{5}=x_{6}$. By Lemma 3 (iii), we obtain the figure below.

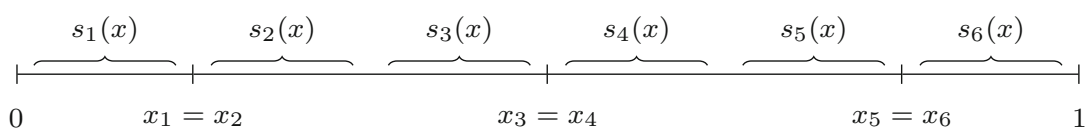

Solving the equalities corresponding to the above figure

$$
\begin{aligned}
a \cdot s_{1}(x) & =a \cdot s_{2}(x) \\
s_{2}(x)+a \cdot s_{2}(x) & =s_{3}(x)+a \cdot s_{3}(x)
\end{aligned}
$$

\footnotetext{
4 Kohlberg (1982) also proves that there is no equilibrium in this case.
} 


$$
\begin{aligned}
a \cdot s_{3}(x) & =a \cdot s_{4}(x) \\
s_{4}(x)+a \cdot s_{4}(x) & =s_{5}(x)+a \cdot s_{5}(x) \\
a \cdot s_{5}(x) & =a \cdot\left(1-z_{5}(x)\right),
\end{aligned}
$$

yields $s(x)=\left(\frac{1}{6}, \frac{1}{6}, \frac{1}{6}, \frac{1}{6}, \frac{1}{6}, \frac{1}{6}\right)$ and thus $x=\left(\frac{1}{6}, \frac{1}{6}, \frac{1}{2}, \frac{1}{2}, \frac{5}{6}, \frac{5}{6}\right)$. Suppose firm 2 locates at $x_{2}^{\prime}=\frac{1}{5}$. Solving

$$
\begin{aligned}
s_{1}\left(x_{2}^{\prime}, x_{-2}\right)-\frac{1}{6}+a \cdot s_{1}\left(x_{2}^{\prime}, x_{-2}\right) & =\frac{1}{5}-s_{1}\left(x_{2}^{\prime}, x_{-2}\right)+a \cdot s_{2}\left(x_{2}^{\prime}, x_{-2}\right) \\
z_{2}\left(x_{2}^{\prime}, x_{-2}\right)-\frac{1}{5}+a \cdot s_{2}\left(x_{2}^{\prime}, x_{-2}\right) & =\frac{1}{2}-z_{2}\left(x_{2}^{\prime}, x_{-2}\right)+a \cdot s_{3}\left(x_{2}^{\prime}, x_{-2}\right) \\
a \cdot s_{3}\left(x_{2}^{\prime}, x_{-2}\right) & =a \cdot s_{4}\left(x_{2}^{\prime}, x_{-2}\right) \\
z_{4}\left(x_{2}^{\prime}, x_{-2}\right)-\frac{1}{2}+a \cdot s_{4}\left(x_{2}^{\prime}, x_{-2}\right) & =\frac{5}{6}-z_{4}\left(x_{2}^{\prime}, x_{-2}\right)+a \cdot s_{5}\left(x_{2}^{\prime}, x_{-2}\right) \\
a \cdot s_{5}\left(x_{2}^{\prime}, x_{-2}\right) & =a \cdot\left(1-z_{5}\left(x_{2}^{\prime}, x_{-2}\right)\right)
\end{aligned}
$$

yields

$$
s_{2}\left(x_{2}^{\prime}, x_{-2}\right)=\frac{(8+5 a) \cdot\left(20+33 a+6 a^{2}\right)}{60 \cdot\left(16+36 a+21 a^{2}+3 a^{3}\right)} .
$$

For this deviation to be unprofitable, we must have $a=0$. This contradicts the assumption that $a>0$.

(2) Assume that $x_{1}=x_{2}<x_{3}=x_{4}<x_{5}<x_{6}$. By Lemma 3 (iii), we obtain the figure below. Note that you can show that there is no SPE with $z_{4}(x)<x_{5}$.

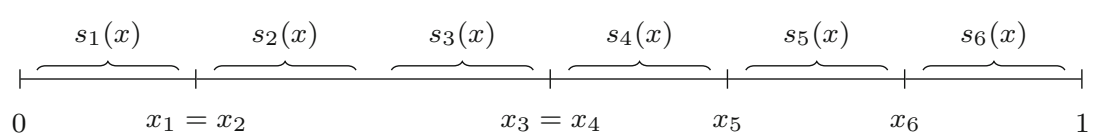

Solving the equalities corresponding to the above figure yields

$$
s_{2}(x)=\frac{a^{2}}{1+3 a+6 a^{2}} .
$$

Suppose firm 2 locates an arbitrary small $\epsilon>0$ to the right. For this deviation to be unprofitable, we must have $a=0$. This contradicts the assumption that $a>0$.

(3) Assume that $x_{1}=x_{2}<x_{3}<x_{4}=x_{5}<x_{6}$. By Lemma 3 (iii), we obtain the figure below. Note that you can show that there is no SPE with $z_{4}(x)<x_{5}$.

$\overbrace{0}^{s_{1}(x)} \overbrace{x_{1}=x_{2}}^{s_{2}(x)} \overbrace{x_{3}}^{s_{3}(x)} \overbrace{x_{4}=x_{5}}^{s_{4}(x)} \overbrace{x_{6}}^{s_{5}(x)} \overbrace{1}^{s_{6}(x)}$


Solving the equalities corresponding to the above figure yields

$$
s(x)=\frac{1+a}{4+6 a} .
$$

Suppose firm 2 locates an arbitrary small $\epsilon>0$ to the right. For this deviation to be unprofitable, we must have $a=0$. This contradicts the assumption that $a>0$.

(4) Assume that $x_{1}=x_{2}<x_{3}<x_{4}<x_{5}=x_{6}$. By Lemma 3 (iii), we obtain the figure below. Note that you can show that there is no SPE with $z_{2}(x)<x_{3}$, or with $z_{4}(x)>x_{4}$.

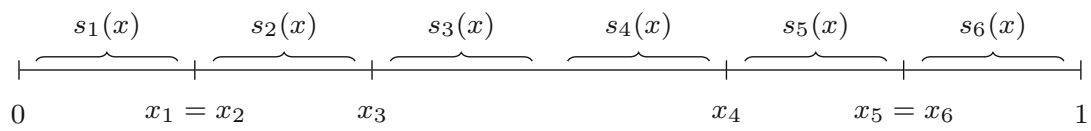

Solving the equalities corresponding to the above figure yields

$$
s_{2}(x)=\frac{a}{2+6 a} \text {. }
$$

Suppose firm 2 locates an arbitrary small $\epsilon>0$ to the right. This deviation is always profitable.

(5) Assume that $x_{1}<x_{2}=x_{3}<x_{4}=x_{5}<x_{6}$. By Lemma 3 (iii), we obtain the figure below.

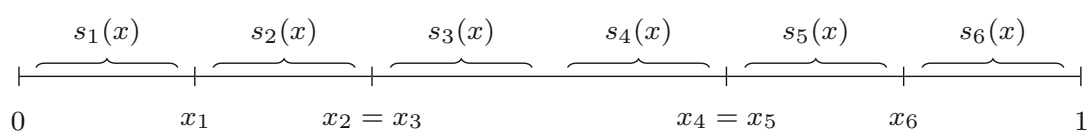

Solving the equalities corresponding to the above figure yields

$$
s(x)=\frac{a}{2+6 a} .
$$

Suppose firm 2 locates an arbitrary small $\epsilon>0$ to the right. For this deviation to be unprofitable, we must have $a=0$. This contradicts the assumption that $a>0$.

(6) Assume that $x_{1}<x_{2}<x_{3}=x_{4}<x_{5}<x_{6}$. By Lemma 3 (iii), we obtain the figure below.

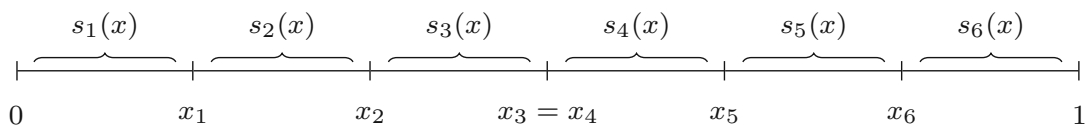

Solving the equalities corresponding to the above figure yields $s(x)=$ $\left(\frac{1+2 a+a^{2}}{2+6 a+6 a^{2}}, \frac{a+a^{2}}{2+6 a+6 a^{2}}, \frac{a^{2}}{2+6 a+6 a^{2}}, \frac{a^{2}}{2+6 a+6 a^{2}}, \frac{a+a^{2}}{2+6 a+6 a^{2}}, \frac{1+2 a+a^{2}}{2+6 a+6 a^{2}}\right)$ and $x=\left(\frac{1+2 a+a^{2}}{2+6 a+6 a^{2}}\right.$, $\left.\frac{1+3 a+2 a^{2}}{2+6 a+6 a^{2}}, \frac{1}{2}, \frac{1}{2}, \frac{1+3 a+4 a^{2}}{2+6 a+6 a^{2}}, \frac{1+4 a+5 a^{2}}{2+6 a+6 a^{2}}\right)$. 
To prove that the strategy profile is an SPE, it is sufficient to check that firm 1 does not want to deviate to the right, firm 2 does not want to deviate to the left nor the right, and firm 3 does not want to deviate to the left.

By Lemma 3 (iii), firm 1 has no incentive to deviate in between $x_{1}$ and $x_{2}$. Since market shares are piecewise linear in the location of firm 1, firm 1 has no incentive to deviate in between $x_{2}$ and $x_{3}$. By symmetry and since there are two additional firms at $x_{5}$ and $x_{6}$, firm 1 has also no incentive to deviate to the right of $\frac{1}{2}$.

Since market shares are piecewise linear in the location of firm 2, we show that firm 2 has no incentive to locate at $x_{2}^{\prime}=x_{1}$ :

$$
s_{2}\left(x_{2}^{\prime}, x_{-2}\right)=\frac{(1+a) \cdot\left(16+56 a+72 a^{2}+39 a^{3}+6 a^{4}\right)}{4 \cdot\left(1+3 a+3 a^{2}\right) \cdot\left(16+36 a+21 a^{2}+3 a^{3}\right)} .
$$

Then we show that firm 2 has no incentive to locate as leftmost firm at $x_{2}^{\prime \prime}=$ $s_{2}\left(x_{2}^{\prime \prime}, x_{-2}\right)$ :

$$
s_{2}\left(x_{2}^{\prime \prime}, x_{-2}\right)=\frac{(1+a) \cdot\left(16+72 a+124 a^{2}+105 a^{3}+44 a^{4}+6 a^{5}\right)}{4 \cdot\left(1+3 a+3 a^{2}\right) \cdot\left(16+72 a+100 a^{2}+47 a^{3}+6 a^{4}\right)} .
$$

Finally we show that firm 2 has no incentive to locate as rightmost firm at $x_{2}^{\prime \prime \prime}=$ $1-s_{2}\left(x_{2}^{\prime \prime \prime}, x_{-2}\right)$ :

$$
s_{2}\left(x_{2}^{\prime \prime \prime}, x_{-2}\right)=\frac{(1+a) \cdot\left(16+72 a+124 a^{2}+101 a^{3}+40 a^{4}+6 a^{5}\right)}{2 \cdot\left(1+3 a+3 a^{2}\right) \cdot\left(16+72 a+100 a^{2}+49 a^{3}+6 a^{4}\right)} .
$$

Since $s_{2}\left(x_{2}^{\prime}, x_{-2}\right)<s_{2}(x), s_{2}\left(x_{2}^{\prime \prime}, x_{-2}\right)<s_{2}(x)$ and $s_{2}\left(x_{2}^{\prime \prime \prime}, x_{-2}\right)<s_{2}(x)$ if $a \geq$ 29.8873, firm 2 has no incentive to deviate.

Since market shares are piecewise linear in the location of firm 3, we show that firm 3 has no incentive to locate at $x_{3}^{\prime}=x_{2}$ :

$$
s_{3}\left(x_{3}^{\prime}, x_{-3}\right)=\frac{a \cdot(2+3 a) \cdot\left(8+18 a+13 a^{2}+2 a^{3}\right)}{4 \cdot\left(1+3 a+3 a^{2}\right) \cdot\left(12+32 a+22 a^{2}+3 a^{3}\right)} .
$$

Then we show that firm 3 has no incentive to locate at $x_{3}^{\prime \prime}=s_{1}\left(x_{3}^{\prime \prime}, x_{-3}\right)+s_{3}\left(x_{3}^{\prime \prime}, x_{-3}\right)$ :

$$
s_{3}\left(x_{3}^{\prime \prime}, x_{-3}\right)=\frac{a \cdot\left(16+76 a+132 a^{2}+111 a^{3}+47 a^{4}+6 a^{5}\right)}{4 \cdot\left(1+3 a+3 a^{2}\right) \cdot\left(4+24 a+42 a^{2}+24 a^{3}+3 a^{4}\right)} .
$$

Finally we show that firm 3 has no incentive to locate as leftmost firm at $x_{3}^{\prime \prime \prime}=$ $s_{3}\left(x_{3}^{\prime \prime \prime}, x_{-3}\right)$ :

$$
s_{3}\left(x_{3}^{\prime \prime \prime}, x_{-3}\right)=\frac{(1+2 a) \cdot\left(4+6 a+a^{2}\right) \cdot\left(4+14 a+19 a^{2}+11 a^{3}+3 a^{4}\right)}{2 \cdot\left(1+3 a+3 a^{2}\right) \cdot\left(16+96 a+204 a^{2}+184 a^{3}+65 a^{4}+6 a^{5}\right)} .
$$

Since $s_{3}\left(x_{3}^{\prime}, x_{-3}\right)<s_{3}(x), s_{3}\left(x_{-3}, x_{3}^{\prime \prime}\right) \leq s_{3}(x)$ and $s_{3}\left(x_{3}^{\prime \prime \prime}, x_{-3}\right)<s_{3}(x)$ if $a \geq$ 29.8873 , firm 3 has no incentive to deviate. 
(7) Assume that $x_{1}=x_{2}<x_{3}<x_{4}<x_{5}<x_{6}$. By Lemma 3 (iii), we obtain the figure below. Note that you can show that there is no SPE with $z_{2}(x)<x_{3}$, or with $z_{3}(x)<x_{4}$, or with $z_{4}(x)<x_{5}$.

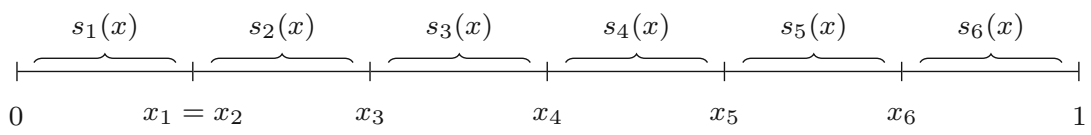

Solving the equalities corresponding to the above figure yields

$$
s_{2}(x)=\frac{a^{4}}{1+5 a+10 a^{2}+10 a^{3}+6 a^{4}} .
$$

Suppose firm 2 locates an arbitrary small $\epsilon>0$ to the right. This deviation is always profitable.

(8) Assume that $x_{1}<x_{2}=x_{3}<x_{4}<x_{5}<x_{6}$. By Lemma 3 (iii), we obtain the figure below. Note that you can show that there is no SPE with $z_{3}(x)<x_{4}$, or with $z_{4}(x)<x_{5}$.

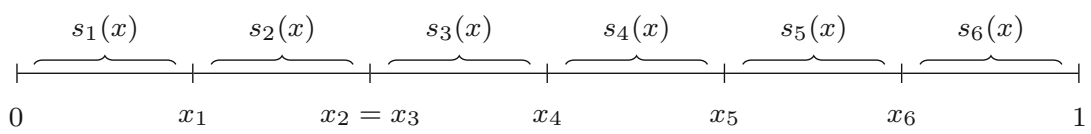

Solving the equalities corresponding to the above figure yields

$$
s_{3}(x)=\frac{(1+a) \cdot a^{2} \cdot a^{3}}{1+4 a+7 a^{2}+6 a^{3}} .
$$

Suppose firm 3 locates an arbitrary small $\epsilon>0$ to the right. This deviation is always profitable.

(9) Assume that $x_{1}<x_{2}<x_{3}<x_{4}<x_{5}<x_{6}$. ${ }^{5}$ We show the proof if $x_{2}<$ $z_{2}(x)<x_{3}, x_{3}<z_{3}(x)<x_{4}$ and $x_{4}<z_{4}(x)<x_{5}$. Other cases can be solved analogously.

Assume $x_{2}<z_{2}(x)<x_{3}, x_{3}<z_{3}(x)<x_{4}$ and $x_{4}<z_{4}(x)<x_{5}$. Solving the equalities yields

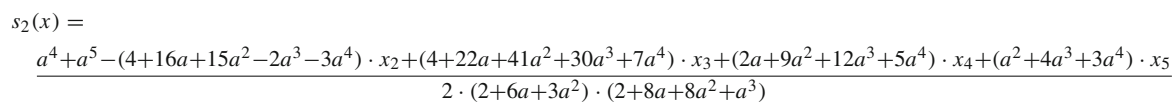

Suppose firm 2 locates an arbitrary small $\epsilon>0$ to the right. For this deviation to be unprofitable, we must have $a=0$. This contradicts the assumption that $a>0$.

$\overline{5 \text { Kohlberg (1982) also proves that there is no equilibrium in this case. }}$ 
Proof (Theorem 7) Assume that $a>0$. By Lemma 3 (iv) and symmetry, we distinguish the following five cases.

(1) Assume that $x_{1}=x_{2}<x_{3}<x_{4}=x_{5}$. By Lemma 3 (ii) and (iv), we obtain the figure below.

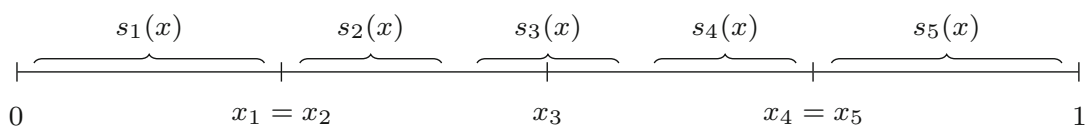

We consider two subcases.

If $z_{2}(x)=x_{3}$, then solving the equalities corresponding to the above figure yields

$$
s_{2}(x)=\frac{a}{3+5 a} .
$$

Suppose firm 2 locates at $x_{2}^{\prime}=x_{3}$. Then

$$
s_{2}\left(x_{2}^{\prime}, x_{-2}\right)=\frac{a \cdot(4+5 a) \cdot\left(4+6 a+a^{2}\right)}{(3+5 a) \cdot\left(16+44 a+32 a^{2}+5 a^{3}\right)} .
$$

For this deviation to be unprofitable, we must have $a=0$. This contradicts the assumption that $a>0$.

If $z_{2}(x)<x_{3}<z_{3}(x)$, then solving the equalities corresponding to the above figure yields

$$
s_{2}(x)=\frac{(3+5 a) x_{3}+a+a^{2}}{9+18 a+5 a^{2}} .
$$

Suppose firm 2 locates at $x_{2}^{\prime}=x_{2}+\epsilon$, where $\epsilon>0$ but arbitrary small. For this deviation to be unprofitable, we must have $a=0$. This contradicts the assumption that $a>0$.

(2) Assume that $x_{1}=x_{2}<x_{3}=x_{4}<x_{5}$. By Lemma 3 (ii) and (iv), we obtain the figure below.

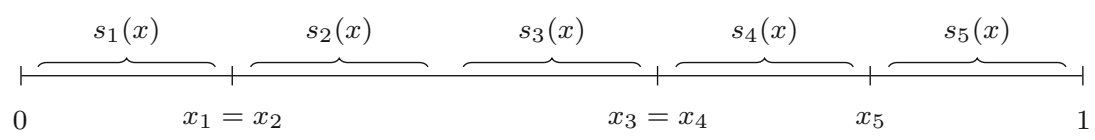

Solving the equalities corresponding to the above figure

$$
s_{2}(x)=\frac{a}{1+5 a} .
$$

Suppose firm 2 locates at $x_{2}^{\prime}=z_{2}\left(x_{2}^{\prime}, x_{-2}\right)$. Then

$$
s_{2}\left(x_{2}^{\prime}, x_{-2}\right)=\frac{a \cdot(2+a) \cdot(3+5 a)}{(1+a) \cdot(1+5 a) \cdot(6+5 a)} .
$$


For this deviation to be unprofitable, we must have $a=0$. This contradicts the assumption that $a>0$.

(3) Assume that $x_{1}<x_{2}=x_{3}<x_{4}<x_{5}$. By Lemma 3 (ii) and (iv), we obtain the figure below.

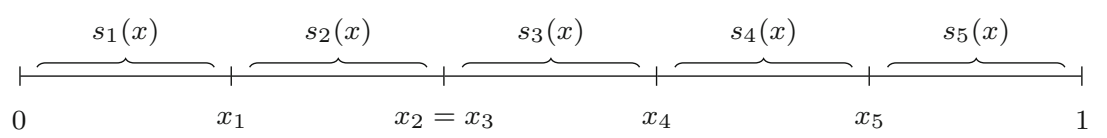

Solving the equalities corresponding to the above figure

$$
s_{3}(x)=\frac{a^{2}}{1+4 a+5 a^{2}} .
$$

Suppose firm 3 locates at $x_{3}^{\prime}=x_{4}$. Then

$$
s_{3}\left(x_{3}^{\prime}, x_{-3}\right)=\frac{a \cdot\left(8+22 a+20 a^{2}+5 a^{3}\right)}{\left(1+4 a+5 a^{2}\right) \cdot\left(12+20 a+5 a^{2}\right)} .
$$

For this deviation to be unprofitable, we must have $a=0$. This contradicts the assumption that $a>0$.

(4) Assume that $x_{1}=x_{2}<x_{3}<x_{4}<x_{5}$. By Lemma 3 (ii) and (iv), we obtain the figure below.

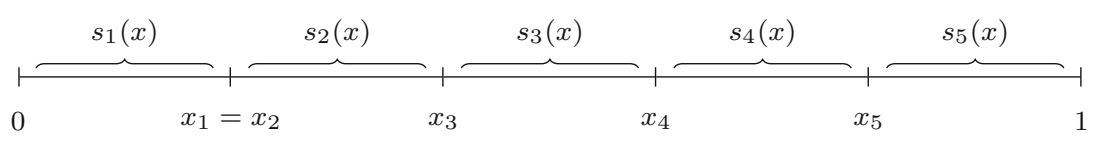

Solving the equalities yields

$$
s_{2}(x)=\frac{a^{3}}{1+4 a+6 a^{2}+5 a^{3}} .
$$

Suppose firm 2 locates at $x_{2}^{\prime}=x_{3}$. Then

$$
s_{2}\left(x_{2}^{\prime}, x_{-2}\right)=\frac{a^{2} \cdot\left(6+10 a+5 a^{2}\right)}{(8+5 a) \cdot\left(1+4 a+6 a^{2}+5 a^{3}\right)} .
$$

For this deviation to be unprofitable, we must have $a=0$. This contradicts the assumption that $a>0$.

(5) Assume that $x_{1}<x_{2}<x_{3}<x_{4}<x_{5}$. ${ }^{6}$ We show the proof if $x_{2}<z_{2}(x)<x_{3}$ and $x_{3}<z_{3}(x)<x_{4}$. Other cases can be solved analogously.

$\overline{6}$ Kohlberg (1982) also proves that there is no equilibrium in this case. 


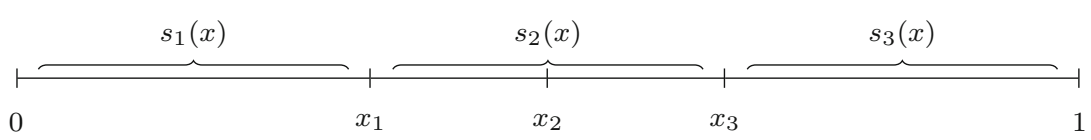

Fig. 6 Three firms at different locations

Assume $x_{2}<z_{2}(x)<x_{3}$ and $x_{3}<z_{3}(x)<x_{4}$. Solving the equalities yields

$$
s_{2}(x)=\frac{a^{3}-\left(2+4 a-2 a^{2}\right) \cdot x_{2}+\left(2+7 a+5 a^{2}\right) \cdot x_{3}+\left(a+3 a^{2}\right) \cdot x_{4}}{(2+5 a) \cdot\left(2+5 a+a^{2}\right)}
$$

Suppose firm 2 locates an arbitrary small $\epsilon>0$ to the right. For this deviation to be unprofitable, we must have $a=0$. This contradicts the assumption that $a>0$.

Proof (Lemma 4) Assume $x_{1}<x_{2}<x_{3}$. By Lemma 3 (iii), we have $x_{1}=s_{1}(x)$ and $x_{3}=1-s_{3}(x)$. See Fig. 6 .

Solving the equalities corresponding to the above figure

$$
\begin{aligned}
a_{1} \cdot s_{1}(x) & =x_{2}-x_{1}+a_{2} \cdot s_{2}(x) \\
x_{3}-x_{2}+a_{2} \cdot s_{2}(x) & =a_{3} \cdot\left(1-z_{2}(x)\right),
\end{aligned}
$$

yields

$$
s_{2}(x)=\frac{a_{3}+a_{1} a_{3}+\left(a_{1}-a_{3}\right) \cdot x_{2}}{1+a_{1}+2 a_{2}+a_{3}+a_{1} a_{2}+a_{1} a_{3}+a_{2} a_{3}} .
$$

Suppose firm 2 locates at $x_{2}^{\prime}=x_{1}$. Then

$$
\begin{aligned}
& s_{2}\left(x_{2}^{\prime}, x_{-2}\right) \\
& \quad=\frac{a_{1} \cdot\left(2 a_{3}+2 a_{1} a_{3}+4 a_{2} a_{3}+a_{1} a_{2} a_{3}+a_{3}^{2}+a_{1} a_{3}^{2}+a_{2} a_{3}^{2}+\left(2+a_{1}+4 a_{2}+a_{3}\right) \cdot x_{2}\right)}{\left(1+a_{1}+2 a_{2}+a_{3}+a_{1} a_{2}+a_{1} a_{3}+a_{2} a_{3}\right) \cdot\left(2 a_{1}+2 a_{2}+a_{1} a_{2}+a_{1} a_{3}+a_{2} a_{3}\right)} .
\end{aligned}
$$

Under the assumption that $x_{1}<x_{2}<x_{3}$,

$$
s_{2}(x) \geq s_{2}\left(x_{2}^{\prime}, x_{-2}\right) \Rightarrow a_{3} \leq a_{1}-2 .
$$

Suppose firm 2 locates at $x_{2}^{\prime \prime}=x_{3}$. Then

$$
\begin{aligned}
& s_{2}\left(x_{2}^{\prime \prime}, x_{-2}\right) \\
& \quad=\frac{a_{3} \cdot\left(2+3 a_{1}+4 a_{2}+a_{3}+a_{1}^{2}+4 a_{1} a_{2}+a_{1}^{2} a_{2}+2 a_{1} a_{3}+a_{1}^{2} a_{3}+a_{1} a_{2} a_{3}-\left(2+a_{1}+4 a_{2}+a_{3}\right) \cdot x_{2}\right)}{\left(1+a_{1}+2 a_{2}+a_{3}+a_{1} a_{2}+a_{1} a_{3}+a_{2} a_{3}\right) \cdot\left(2 a_{2}+2 a_{3}+a_{1} a_{2}+a_{1} a_{3}+a_{2} a_{3}\right)} .
\end{aligned}
$$

Under the assumption that $x_{1}<x_{2}<x_{3}$,

$$
s_{2}(x) \geq s_{2}\left(x_{2}^{\prime \prime}, x_{-2}\right) \Rightarrow a_{3} \geq a_{1}+2 .
$$




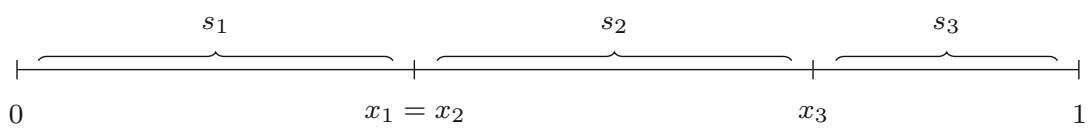

Fig. 7 Two out of three firms locate at the same location

Since $a_{3} \leq a_{1}-2$ and $a_{3} \geq a_{1}+2$ are incompatible, firm 2 always has a profitable deviation.

Proof (Theorem 9) Let $x$ be an SPE. By Lemma 3 (iii), we have $x_{1}=s_{1}(x)$ and $x_{3}=1-s_{3}(x)$. Lemma 4 implies $x_{1}=x_{2}$ or $x_{2}=x_{3}$. We show the analysis for $x_{1}=x_{2}$. A symmetric argument can be given for $x_{2}=x_{3}$.

Let $x_{1}=x_{2}$. By Lemma 3 (iv), we have $a_{1}=a_{2}$ and thus $s_{1}(x)=s_{2}(x)$. See Fig. 7.

Solving the equalities corresponding to the above figure

$$
\begin{aligned}
a_{2} \cdot s_{1}(x) & =a_{2} \cdot s_{2}(x) \\
s_{2}(x)+a_{2} \cdot s_{2}(x) & =a_{3} \cdot\left(1-z_{2}(x)\right),
\end{aligned}
$$

yields $s(x)=\left(\frac{a_{3}}{1+a_{2}+2 a_{3}}, \frac{a_{3}}{1+a_{2}+2 a_{3}}, \frac{1+a_{2}}{1+a_{2}+2 a_{3}}\right)$ and thus $x=\left(\frac{a_{3}}{1+a_{2}+2 a_{3}}\right.$, $\left.\frac{a_{3}}{1+a_{2}+2 a_{3}}, \frac{2 a_{3}}{1+a_{2}+2 a_{3}}\right)$. Note that $a_{3}>0$, since otherwise $s_{1}(x)=s_{2}(x)=0$ and then firm 1 has an incentive to locate at 1.

Suppose firm 2 locates at $x_{2}^{\prime}=x_{3}$. Then

$$
s_{2}\left(x_{2}^{\prime}, x_{-2}\right)=\frac{a_{3} \cdot\left(2+3 a_{2}+a_{3}+a_{2}^{2}+2 a_{2} a_{3}\right)}{\left(1+a_{2}+2 a_{3}\right) \cdot\left(2 a_{2}+2 a_{3}+a_{2}^{2}+2 a_{2} a_{3}\right)} .
$$

So

$$
s_{2}(x) \geq s_{2}\left(x_{2}^{\prime}, x_{-2}\right) \Rightarrow a_{3} \geq a_{2}+2 .
$$

To prove that the strategy profile is an SPE, it is sufficient to check that firm 2 does not want to deviate to the right, and firm 3 does not want to deviate to the left.

Since market shares are piecewise linear in the location of firm 2, firm 2 has no incentive to locate at $x_{2}^{\prime}$, with $x_{2}<x_{2}^{\prime} \leq x_{3}$. Since $1-s_{2}\left(x_{2}^{\prime}, x_{-2}\right)<x_{3}$ if $x_{2}^{\prime}=x_{3}$, there is also no incentive for firm 2 to locate as the rightmost firm.

Observe that firm 3 could only improve by being the leftmost firm. Suppose firm 3 locates as leftmost firm at $x_{3}^{\prime}=s_{3}\left(x_{3}^{\prime}, x_{-3}\right)$. Then

$$
s_{3}\left(x_{3}^{\prime}, x_{-3}\right)=\frac{\left(1+a_{2}\right) \cdot\left(a_{2}+2 a_{3}\right)}{\left(1+a_{2}+2 a_{3}\right) \cdot\left(2+a_{2}+2 a_{3}\right)} .
$$

Since $s_{3}\left(x_{3}^{\prime}, x_{-3}\right)<s_{3}(x)$ if $a_{3} \geq a_{2}+2$, firm 3 has no incentive to deviate.

Hence the strategy profile is an SPE. 


\section{References}

Ahlin C, Ahlin P (2013) Product differentiation under congestion: Hotelling was right. Econ Inq 51:17501763

d'Aspremont C, Jaskold Gabszewicz J, Thisse JF (1979) On Hotelling's “stability in competition”. Econometrica 47:1145-1150

De Palma A, Leruth L (1989) Congestion and game in capacity: a duopoly analysis in the presence of network externalities. Annales d'Economie et de Statistique 15-16:389-407

Downs A (1957) An economic theory of political action in a democracy. J Political Econ 65:135-150

Eaton B, Lipsey R (1975) The principle of minimum differentiation reconsidered: some new developments in the theory of spatial competition. Rev Econ Stud 42:27-49

Fournier G (2016) General distribution of consumers in pure hotelling games. arXiv:1602.04851

Fournier G, Scarsini M (2014) Hotelling games on networks: efficiency of equilibria. Documents de travail du Centre d'Economie de la Sorbonne 14033, Université Panthéon-Sorbonne (Paris 1), Centre d'Economie de la Sorbonne

Friedman J, Grilo I (2005) A market with a social consumption externality. Jpn Econ Rev 56:251-272

Grilo I, Shy O, Thisse JF (2001) Price competition when consumer behavior is characterized by conformity or vanity. J Public Econ 80:385-408

Heikkinen R (2014) A spatial economic model under network externalities: symmetric equilibrium and efficiency. Oper Res 14:89-111

Hotelling H (1929) Stability in competition. Econ J 39:41-57

Kohlberg E (1982) Equilibrium store locations when consumers minimize travel time plus waiting time. hBS working paper 82-02. Harvard University, Boston

Kohlberg E (1983) Equilibrium store locations when consumers minimize travel time plus waiting time. Econ Lett 11:211-216

Lambertini L, Orsini R (2013) On hotelling's 'stability in competition' with network externalities and switching costs. Pap Reg Sci 92:873-883

Navon A, Shy O, Thisse JF (1995) Product differentiation in the presence of positive and negative network effects. Centre for Economic Policy Research

Núñez M, Scarsini M (2016) Competing over a finite number of locations. Econ Theory Bull 4:125-136

Núñez M, Scarsini M (2017) Large spatial competition. Spat Interaction Models 225-246

Osborne M, Pitchik C (1987) Equilibrium in hotelling's model of spatial competition. Econometrica 55:911922

Pálvölgyi D (2011) Hotelling on graphs. http://media.coauthors.net/konferencia/conferences/5/palvolgyi. pdf

Salop S (1979) Monopolistic competition with an outside good. Bell J Econ 10:141-156

Tian J (2015) Optimal interval division. SSRN. http://doi.org/10.2139/ssrn.2697430 